\title{
Effect of Short Term Aging on Organic Montmorillonite Nanoclay Modified Asphalt
}

\author{
Lamya M. J. Mahdi ${ }^{1 *}$, Ratnasamy Muniandy ${ }^{1}$, Robiah Bt. Yunus², Salihudin Hasham', \\ Eltaher Aburkaba ${ }^{1}$ \\ 'Department of Civil Engineering, Faculty of Engineering, University Putra Malaysia, \\ 43400 UPM, Serdang, Selangor Darul Ehsan, Malaysia; laal20042003@yahoo.com, ratna@upm.edu.my, \\ hsalih@upm.edu.my, eltaher@upm.edu.my \\ ${ }^{2}$ Department of Chemical Engineering, Faculty of Engineering, \\ University Putra Malaysia, 43400 UPM, Serdang, Selangor Darul Ehsan, Malaysia; robiah@upm.edu.my
}

\begin{abstract}
In order to increase the life of bituminous pavement, quality of bitumen needs to be enhanced and modified. The objective of this study was to evaluate the conventional and rheological properties of binders containing various percentages of organic montmorillonite nanoclay particles before and after a short-term aging process. Two types of organic montmorillonite nanoclay (N3 and N4) were chosen to blend with 80/100 base asphalt in various concentrations (3\%, 7\% and 9\%) by weight of the asphalt and subjected to aging using the Rolling Thin Film Oven in order to simulate short term aging. The conventional properties of organic montmorillonite nanoclay modified bituminous binders before and after aging were characterized using retained penetration, increment in softening point, and viscosity aging index concepts while the rheological properties were characterized in terms of their complex shear modulus, phase angle, overall resistance to deformation, and their viscoelastic behavior were measured at higher temperatures ranging from 40 to $82^{\circ} \mathrm{C}$ using Dynamic Shear Rheometer. The test results showed that the introducing of organic montmorillonite nanoclay to the asphalt binder improves the aging effect on the conventional and fundamental properties as compared to unaged modified asphalt. This improvement can recognized through the higher retained penetration and lower increment in softening point as well as viscosity aging index. Also, the result showed remarkable improvement in rutting resistance of the aged modified binder which results in better resistance to permanent deformation at intermediate and high temperature. Compared between the two types of nanoclay, N3 showed better enhancement to the conventional and rheological properties of asphalt binders and exhibited greater resistance to rutting before and after aging process, which can be contributed to the better dispersion of clay layers of N3 inside asphalt binder that refer to the types of surface treatment of the montmorillonite nanoclay.
\end{abstract}

Keywords: Nanoclay, Modified Asphalt, Conventional, Fundamental Properties, RTFO Aging, Rutting Resistance.

\section{Introduction}

One of the most important issues that facing asphalt pavement researchers is the kind of modifier that can improve the properties of asphalt binder to provide longer service life, less maintenance, cheaper, and environmental friendly asphalt pavements. During its service life, asphalt pavement experience premature failures such as fatigue, rutting, thermal cracking, and moisture induced damage, this lead to urgent resolution to limit or at least delay this kind of failure which costing the road authority a lot of money with the ever increasing of crude oil prices. However, researchers and engineers have been challenged to explore whether the optimum physical characteristics of nanoparticles can exhibit the best performance as an asphalt binder modifier. This has raised the need for more research utilizing nanotechnology to improve the rheological and engineering characteristics of asphalt binders and to develop some

${ }^{*}$ Corresponding author:

Lamya M. J. Mahdi (laal20042003@yahoo.com) 
guidelines for its use $[1,2]$. In the last decade, the orientation towards nanotechnology using nanomaterial showed promising results in improving asphalt binder properties due to its small particles size compared with other modified materials which make it easy to be compatible with other materials to create nanocomposite and the positive results that gained from adding nanoclay to polymer gave the pavement researchers motivation to adopt this material which enable them to study the asphalt binder behavior at nano scale level $[3,4,5,6,7]$.

Montmorillonite nanoclay was selected by the researcher to modify bitumen with different mass contents as the 2:1 type layer structure makes it more compatible with others material. Recently, few researchers tried to use nanoclay to improve the rutting and cracking resistances of asphalt mixtures. Ghile investigated the effect of the addition of two types of nanoclay (cloisite and, nanofill) on asphalt binder and mixture. The results indicated improvement in some characteristics of asphalt binder and mixtures such as stiffness, rutting, and aging resistance of the binder as well as indirect tensile strength and dynamic creep for the mixture and the nanoclays were observed to negatively influence the fatigue resistance performance of asphalt binders and mixture especially at low temperature [8]. Jianying $\mathrm{Yu}$ used two types of nanoclay, inorganic montmorillonite and organic montmorilloniteto modify bitumen. The tests results showed that the organic montmorillonite showed better improvement in physical and rheological properties at high temperature [9]. In another study Jianying tested three types of organic montmorillonite nanoclay which prepared by adding different organic modifiers (OMMT1, OMMT2, and OMMT3), tests results indicates improvement in; aging resistance and some of physical properties like softening point and viscosity of the OMMT modified bitumen. The degree of improvement depends on the types of the organic modifier [10]. Jahromi adopted Cloiste-15A and Nanofil-15 to modified bitumen, tests on binder and mixture improved properties like stiffness, stability, resilient modulus, and indirect tensile strength [11]. Shaopeng $\mathrm{Wu}$, has chosen organic nano-montmorillonite to prepare the nanoclay modified asphalt, the study evaluate the fatigue resistance property of the modified asphalt, the results showed that the modified asphalt containing nanoclay suggests excellent fatigue resistance [12]. In another study, the thermal properties and morphology of organic montmorillonite nanoclay with different mass contents was investigatedbefore and after aging. The results indicate improvement in aging properties of the organic montmorillonite nanoclay modified bitumen [13].

\section{Materials and Methods}

\subsection{Materials}

One asphalt binder 80/100 penetration grade obtained from KRIP, Kajang Rocks Innopave Premix Company in Malaysia was used in this study. The properties of the virgin asphalt binder are shown in Table 1. Commercially available nanoparticles were utilized in this research; two types of organic montmorillonite nanoclay namely $(\mathrm{N} 3$ and $\mathrm{N} 4)$ were provided by Fenghong Clay Chemical Factory, Zhejiang, China. The nanoclay properties are shown in Table 2.

\subsection{Preparation of OMMT/Asphalt Binders}

Three percentages $(3.0,5.0$, and $9.0 \%$ by weight of the virgin binder) of nanoparticles and the control binder were employed and blended with the virgin asphalt binder. The asphalt binder was heated in an oven until melted and poured in a container. The blend was prepared by adding the predetermined amount of nanoclay material gradually around $1 \mathrm{~g}$ /minute to the hot binder at established mixing temperatures of $150 \pm 5^{\circ} \mathrm{C}$ at speed of $500 \mathrm{rpm}$; the blend was mechanically mixed on an electric

Table 1. Physical properties of unaged $80 / 100$ penetration grade base asphalt

\begin{tabular}{lcl}
\hline Physical Properties & Result & Specification \\
\hline Penetration@25 $5^{\circ} \mathrm{C},(\mathrm{dmm})$ & 80 & ASTM D5 \\
Softening Point $\left({ }^{\circ} \mathrm{C}\right)$ & 46.5 & ASTM D36 \\
Viscosity@135 $5^{\circ} \mathrm{C},(\mathrm{Pa} . \mathrm{s})$ & 0.379 & ASTM D4402 \\
$\mathrm{G}^{*} /$ sin $\delta @ 64^{\circ} \mathrm{C}(\mathrm{kPa})$ & 1.21 & AASHTO TP5 \\
Ductility @25 ${ }^{\circ} \mathrm{C}(\mathrm{cm})$ & $>100$ & ASTM D113 \\
Specific Gravity $\left(\mathrm{g} / \mathrm{cm}^{3}\right)$ & 1.03 & ASTM D70 \\
\hline
\end{tabular}

Table 2. Nanoclay properties

\begin{tabular}{lll}
\hline Physical Properties & \multicolumn{2}{c}{ Nanoclay Type } \\
\cline { 2 - 3 } $\begin{array}{l}\text { Organic } \\
\text { Montmorillonite } \\
\text { Treatment }\end{array}$ & $\begin{array}{l}\text { Nimethyl benzyl } \\
\text { (hydrogenated } \\
\text { tallow alkyl) } \\
\text { ammonium cations }\end{array}$ & $\begin{array}{l}\text { Dimethyl di } \\
\text { (hydrogenated } \\
\text { tallow alkyl) } \\
\text { ammonium } \\
\text { cations }\end{array}$ \\
CEC & $90-120$ & $\begin{array}{l}\text { No-120 } \\
\text { mmol/100g }\end{array}$ \\
Color & whol/100g & white \\
Appearance & fine \\
X Ray Diffraction & $\mathrm{d}=2.8$ & $\mathrm{~d}=3.8$ \\
Properties $\mathrm{d}_{001} \mathrm{~nm}$ & & \\
\hline
\end{tabular}


hot-plate set using IKA Labortechnik, RW 20 DZM.n mechanical mixer. After the completion of nanoclay addition, the blend was stirred for 60 minutes at speed of $2000 \mathrm{rpm}$ while maintaining a temperature of $150^{\circ} \mathrm{C}$ to insure that the nanoclay particles were homogenously and well dispersed inside the medium of asphalt binder.

\subsection{Aging Procedure}

Aging or hardening is a major factor that affects the durability of asphalt pavement. Aging of asphalt cement occurs during the mixing and laydown process and during service [14]. It is well known that the asphalt binder age due to two phenomena: volatilization (the loss of light oils in the asphalt) and oxidation (the reaction with oxygen from the environment). While manufacturing and laydown of asphalt paving mixtures, binders age due to both phenomena because of the high temperature and air flow involved in the process [15]. The Rolling Thin Film Oven (RTFO) was used for simulation the short term aging that occurs in asphalt binder during manufacturing and construction of asphalt pavement. The RTFO test was carried out according to the requirement of AASHTO T-240 Standard [16] by measuring the effect of heat and air on a moving film of semisolid asphalt binder. The base and organic montmorillonite nanoclay OMMT modified asphalt samples were aged at $163{ }^{\circ} \mathrm{C}$ and air flow $4000 \mathrm{ml} / \mathrm{min}$ for 85 minute.

\subsection{Conventional Properties of Unaged and Aged Base and OMMT Modified Asphalt}

The conventional or physical properties of the base and OMMT nanoclay modified asphalt where tested before and after RTFO aging to characterized the consistency of binder including Penetration in accordance to ASTM D5 [17], Softening Point in accordance to ASTM D36 [18] and Viscosity at two different testing temperature $135^{\circ} \mathrm{C}$ and $165^{\circ} \mathrm{C}$ using Brookfield Viscometer in accordance to ASTM D4402 [19].

\subsection{Fundamental Properties of Unaged and RTFO-aged Base and OMMT Modified} Asphalt

The fundamental (rheology) properties of the binder are a major factor that influences the permanent deformation of asphalt pavement. Dynamic Shear Rheoemeter (DSR) model (HAAKE/RheoStress RS1/Phoenix) was used for measuring the rheological properties and the viscoelastic behavior of the base and OMMT modified binder before and after aging. Using a $25 \mathrm{~mm}$ diameter spindle and $1 \mathrm{~mm}$ gap, each sample was compressed between two parallel plates (one of which is fixed and the other is oscillates) and subjected to sinusoidal shear stress. The temperature steps test was performed between 40 and $82^{\circ} \mathrm{C}$ with 6 degree increment, at fixed frequency of $10 \mathrm{rad} / \mathrm{sec}$ $(1.592 \mathrm{~Hz})$ in controlled stress mode of $120 \mathrm{~Pa}$ for unaged and $220 \mathrm{~Pa}$ for RTFO aged samples in accordance to Strategic Highway Research Program (SHRP) asphalt binder specifications [20]. The DSR test measured the complex shear modulus $\left(G^{*}\right)$ and phase angle $(\delta)$ where the complex shear modulus $\left(\mathrm{G}^{*}\right)$ represents the total resistance of a binder to deform while exposed to repeated pulses of shear stress, and the phase angle $(\delta)$ is an indicator of the relative amounts of the recoverable and non-recoverable deformation $[21,22]$. The DSR rutting factor, $G^{*} / \sin \delta$, was used to measure the stiffness at intermediate and high temperature and rutting resistance of asphalt binders [23]. The SHRP Superpave PG binder specifies minimum values for $\mathrm{G}^{*} / \sin \delta$ of $1000 \mathrm{~Pa}$ for original asphalt binder, $2200 \mathrm{~Pa}$ after Rolling Thin Film Oven (RTFO) aging and $5000 \mathrm{kPa}$ after Pressure Aging Vessel (PAV) procedure [24].

\section{Results and Discussion}

\subsection{Physical Properties of Unaged Base and Nanoclay Modified Asphalt Binder}

The results of physical tests carried out on unaged nanoclay modified asphalt binder for both types at different concentration are presented in Figure 1. It can be noticed that there is improvement in penetration, softening point and viscosity for both N3 and N4 modified asphalt compared to the non-modified asphalt. The addition of OMMT to asphalt led to decrease in penetration, increase in softening point and viscosity at both testing temperature. This improvement is related to the increasing of nanoclay particles content in asphalt binder. The asphalt binder with 9\% nanoclay particles showed the highest viscosity value compared to the other nanoclay modified binders and all samples were within the specified maximum viscosity of 3 Pas at $135^{\circ} \mathrm{C}$ specifications requirement. The main reason of this improvement after adding the various OMMT concentrations due to the better dispersion of the OMMT layers in bitumen that reinforced it by restrict the flow of bitumen make it stiffer. In another word the existing of the nanoclay particles strengthen the bonding with bitumen which leads to improve its physical properties. As compared to N4, N3 showed lower values of penetration and higher 
softening point and viscosity values, which could be related to the type of organic treatment that used to modify both nanoclay leading to better dispersion of nanoclay particles in bitumen and forming an exfoliated (layered) structure.

\subsection{Physical Properties of Aged Base and Nanoclay Modified Asphalt Binder}

The retained penetration (RP), increment in softening point (ISP), and viscosity aging index (VAI) concepts were used to characterize the effect of nanoclay type (N3 and N4) and concentration on aging properties of asphalt binder using the following equations:

The retained penetration was calculated using equation 1 .

$$
\mathrm{RP} \%=\frac{\text { Aged Penetration value }}{\text { Unaged Penetration value }} \times 100
$$

The increment in softening point was calculated using equation 2

$$
\begin{array}{r}
\text { ISP }=\text { Aged softening point value }- \\
\text { Unaged softening point value }
\end{array}
$$
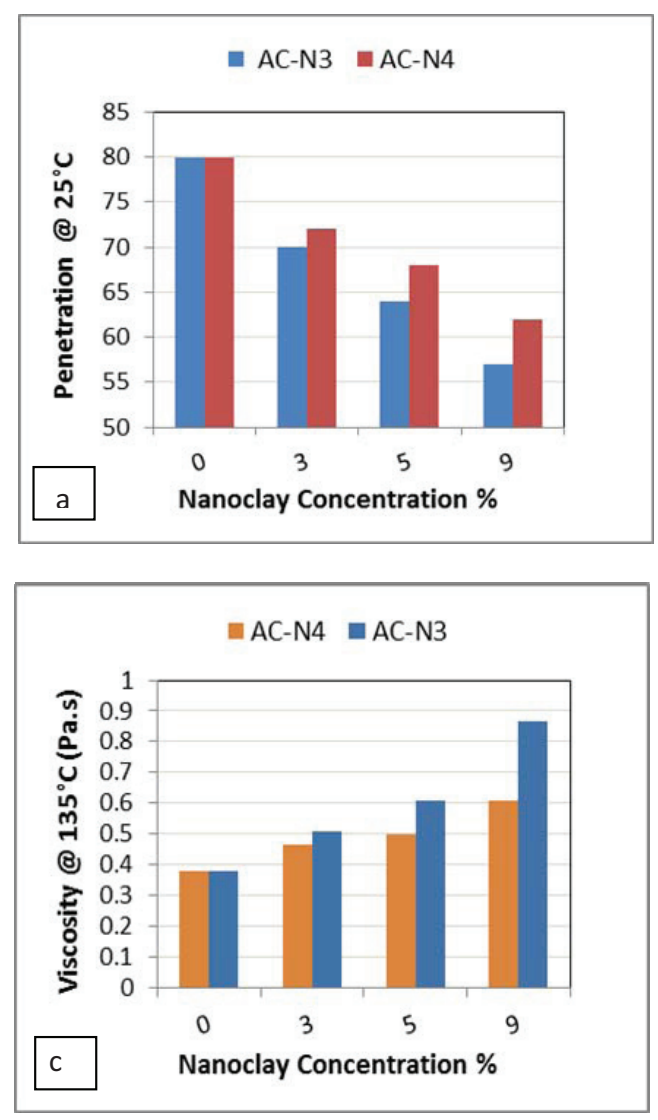

The viscosity aging index was calculated using equation 3 $\mathrm{VAI} \%=$

$\frac{\text { Aged viscosity value }- \text { Unaged viscosity value }}{\text { Unaged viscosity value }} \times 100$

Figure 2(a) indicates that the retained penetration increases by increasing the nanoclay concentration for all samples and in terms of nanoclay type, $\mathrm{N} 3$ showed better retained penetration compared to N4. This could be related to the increase of consistency by increasing the OMMT concentration in binder which makes it harder to flow as the particles of nanoclay disperse in binder. Figure 2(b) shows the variation in softening point values with the various concentrations of OMMTs. The softening point for all OMMTs modified samples increased after RTFO aging process compared to the unaged samples. In another word, the addition of OMMTs in different concentration to asphalt binder can improve the aging resistance of binder and make it more resist to the high temperature and as consequence lead to increase the resistance to deformation and rutting.
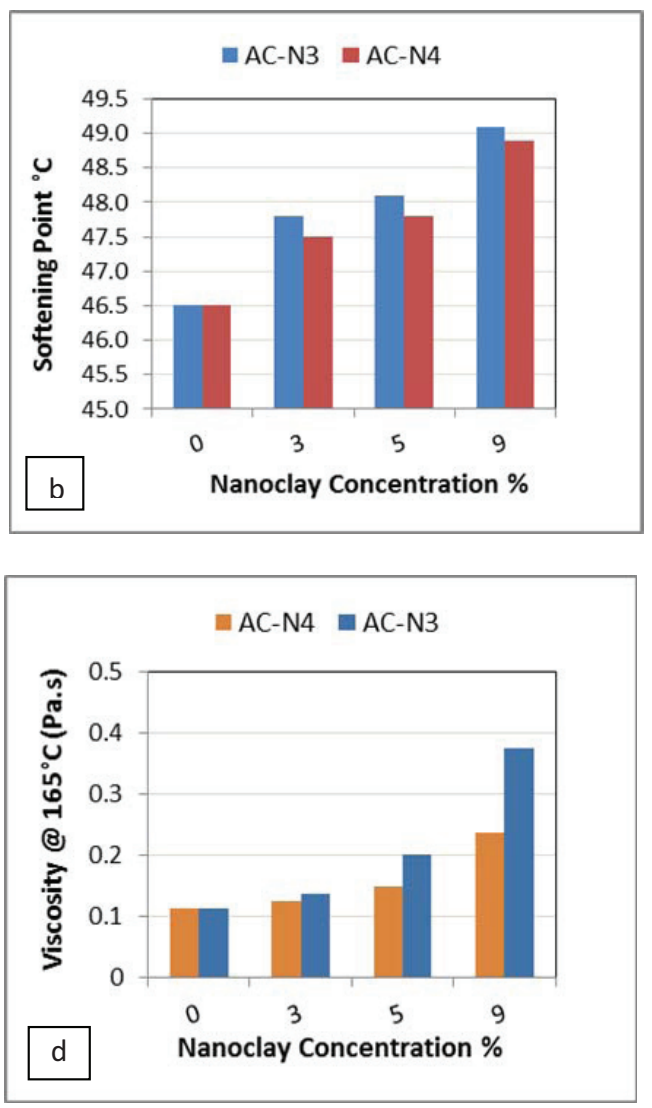

Figure 1. Effect of variation of $\mathrm{N} 3$ and $\mathrm{N} 4$ concentration in binder on (a) Penetration (b) Softening point (c) Viscosity@135 ${ }^{\circ} \mathrm{C}$, and (d) Viscosity@165 $\mathrm{C}$. 
The viscosity aging index results as shown in Figure 2(c) indicates that the viscosity aging index of OMMTs modified binder decreasing as the amount of nanoclay increased for both types of nanoclay. In terms of nanoclay type N3 showed better resistance to aging compared to N4. The increment of the aging resistance of binder after nanoclay modification is due to the better dispersion of the silicate platelet nanoclay particles inside the binder which restrict the moving of bitumen, forming an intercalated or even exfoliated structure.

\subsection{Dynamic Rheological Properties of Unaged Nanoclay Modified Asphalt Binder}

The variation in viscoelastic behavior and rheological properties of asphalt binders before aging at intermediate to high temperatures was characterized using the Dynamic Shear Rheometer (DSR). The test results are shown in Figures 3 and 4 which illustrate the variation of binder's complex modulus and phase angle, respectively, versus different OMMTs concentration before aging process.
With reference to Figure 3 and 4 a general trend was observed that all specimens showed decrease in complex modulus values and an increase in phase angle as the temperature increases. The OMMT modified binder showed higher complex modulus throughout the temperature range compared to original binder and it can be seen that with increasing organic montmorillonite contents, the $\mathrm{G}^{*}$ value of the modified asphalts increases significantly. The higher complex modulus and lower phase angle can be refers to binder strength increment after the modification with nanoclay particles as it disperse symmetrically which can form exfoliated structure resulting in stiffer and higher rutting resistance of modified asphalt binder.

Rutting in the upper pavement layers is caused by the accumulated plastic deformation in the mixture that results from the repeated application of traffic loading. The rutting factor $\mathrm{G}^{*} / \sin \delta$, was selected by the Strategic Highway Research Program (SHRP) specifications to express the contribution of the asphalt binder to permanent deformation [25]. Since rutting is more prevalent at intermediate and high temperatures than at low temperatures,

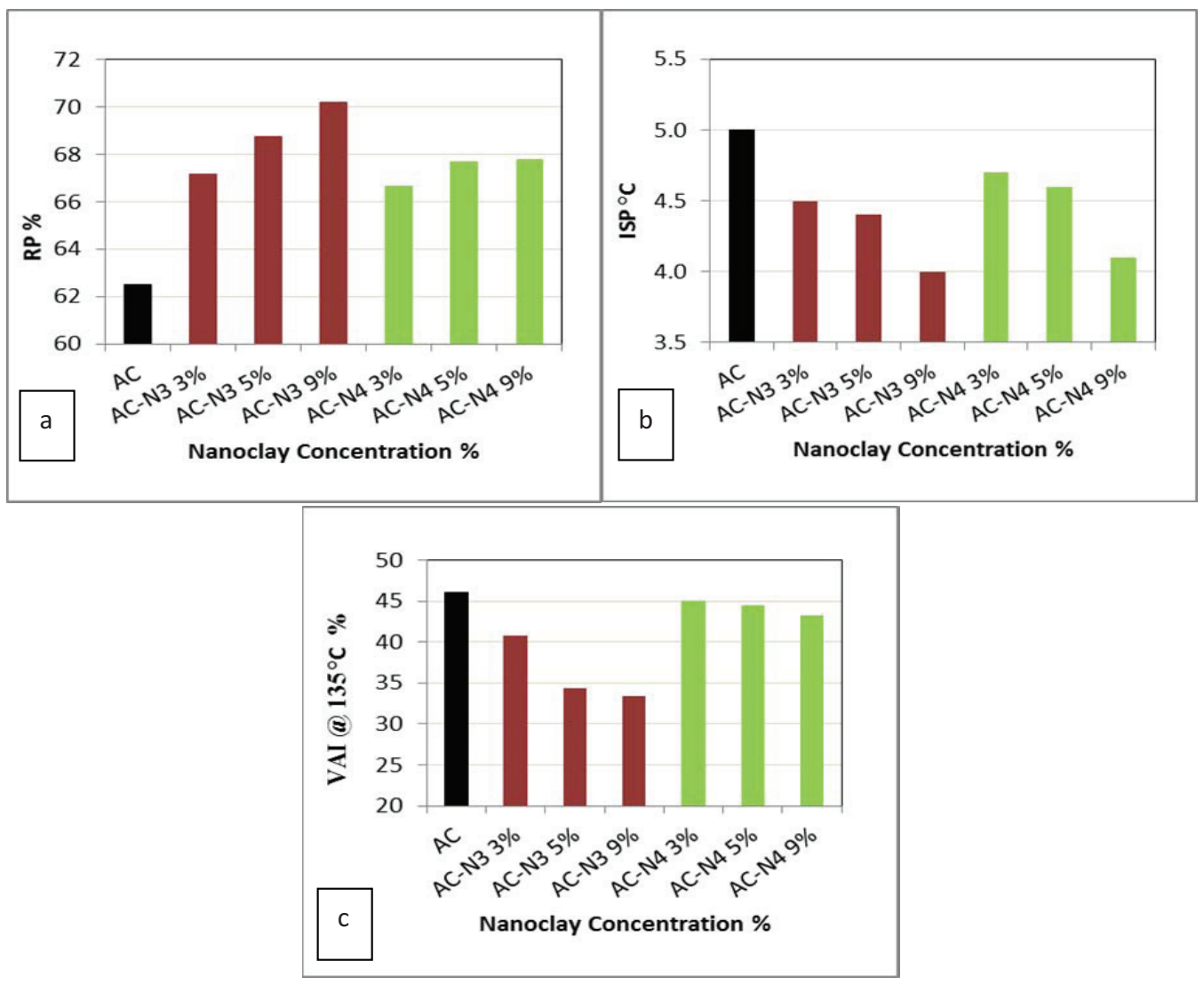

Figure 2. Effect of nanoclay type and concentration on aging properties of binder: (a) Retained penetration (b) Increment in softening point (c) Viscosity aging index@ $135^{\circ} \mathrm{C}$. 


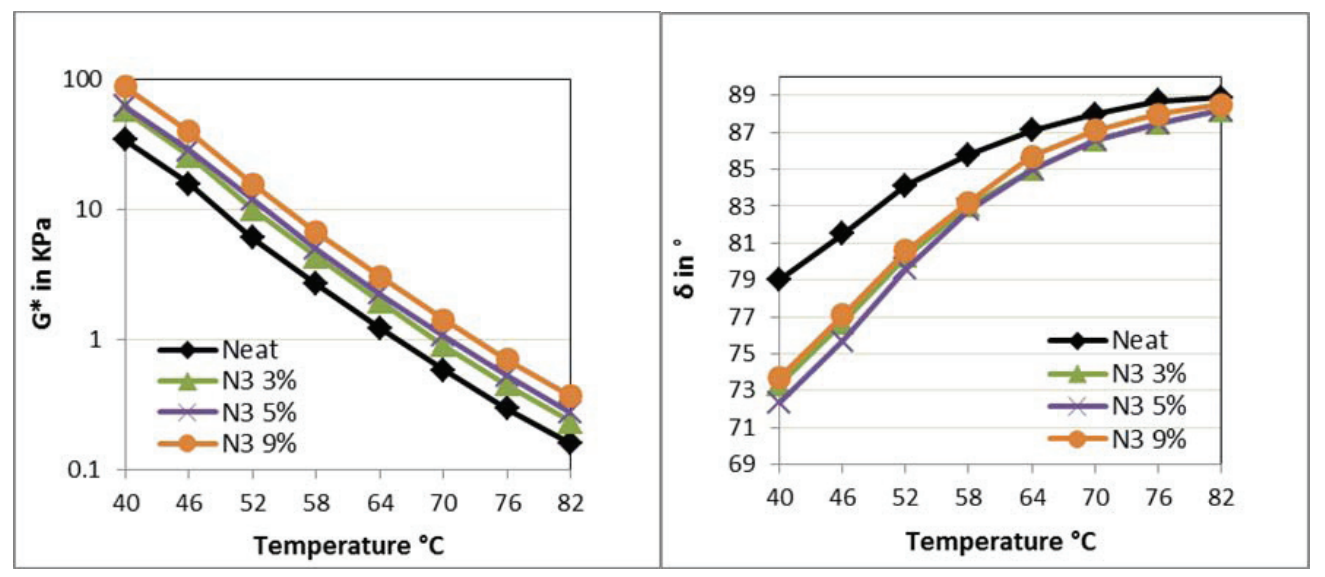

Figure 3. The complex shear modulus $\left(\mathrm{G}^{*}\right)$ and phase angles $(\delta)$ variation vs. temperature for N3 modified binder before aging.

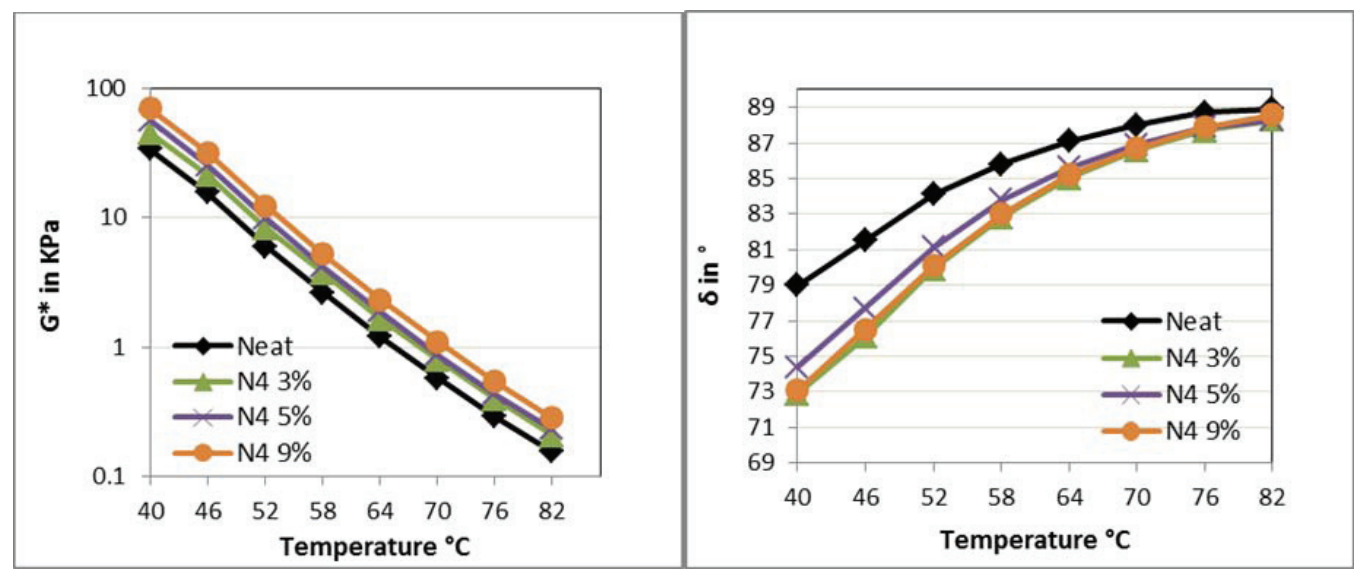

Figure 4. The complex shear modulus $\left(\mathrm{G}^{*}\right)$ and phase angles $(\delta)$ variation vs. temperature for N4 modified binder before aging.

the properties related to rutting should therefore be measured in the upper range of pavement service temperatures. In this study a reference high test temperature of $64^{\circ} \mathrm{C}$ was selected to reflect the rutting temperature, as rutting is expected to occur when the temperature is near the maximum bituminous pavement temperature on a hot summer day which is around $60^{\circ} \mathrm{C}$ so it is suggested to determine the stiffness of the bitumen at this temperature to specify the minimum stiffness and thus ensure adequate resistance to rutting during hot summer [26]. Figure 5 illustrates that the rutting parameters increases, as the amount of OMMT increased which reflects the increment of the binder resistance to deformation under repeated load. Nanoclay type $\mathrm{N} 3$ has shown higher rutting resistance value than N4 modified binders at the same percentage of nanoclay modifier.

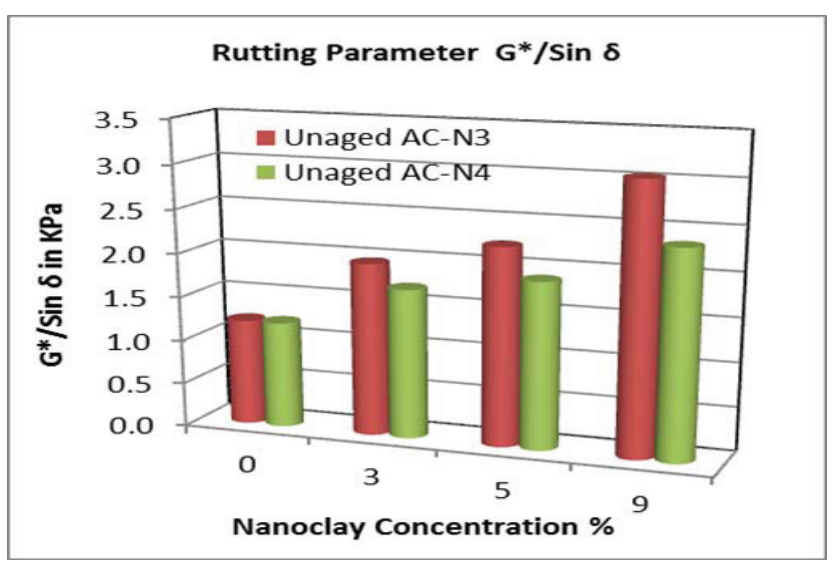

Figure 5. Variation of rutting parameter $\left(\mathrm{G}^{*} / \sin \delta\right)$ of $\mathrm{N} 3$ and $\mathrm{N} 4$ concentration at $64^{\circ} \mathrm{C}$ before aging. 


\subsection{Dynamic Rheological Properties Aged Nanoclay Modified Asphalt Binder}

The N3 and N4 modified and unmodified asphalt binder after RTFO aging process are subjected to the DSR test under same circumstance to see the effect of OMMTs on the rheological properties of binder after aging, the test results are shown in Figure 6 and 7. It can be seen that there is a remarkable improvement in the complex shear modulus and phase angle compared to the unmodified asphalt for both types of nanoclay modifiers. With the increase in nanoclay concentration, the complex modulus and phase angle improved tremendously; the higher concentration the higher effect on the rheological properties of asphalt binder. This indicated that both N3 and N4 had positive effect on aging resistance of modified samples which decrease the temperature susceptibility but reduces the effect of oxygen due to the existing of silicate platelet that obstruct the permeating of oxygen and thus limit from its effect. All this can truly happen if the layered silicate of organic nanoclay disperse symmetrically in the asphalt matrix to build the strong bonding strength with asphalt binder.

The rutting factor, $\mathrm{G}^{*} / \sin \delta$ results are shown in Figure 8 at reference temperature of $64^{\circ} \mathrm{C}$. A general trend was observed that the rutting parameters increased as the concentration of OMMTs increases. This trend indicates that the addition of $\mathrm{N} 3$ and $\mathrm{N} 4$ (compared to non-modified binder) led the binder to be more elastic which reflects the increment of the binder resistance to deformation under repeated load and result in substantial rutting resistance. Tests results in Figure 8 also showed that N3 has higher $\mathrm{G}^{*} / \sin \delta$ values than $\mathrm{N} 4$ at the three selected nanoclay concentrations which indicate better performance of N3

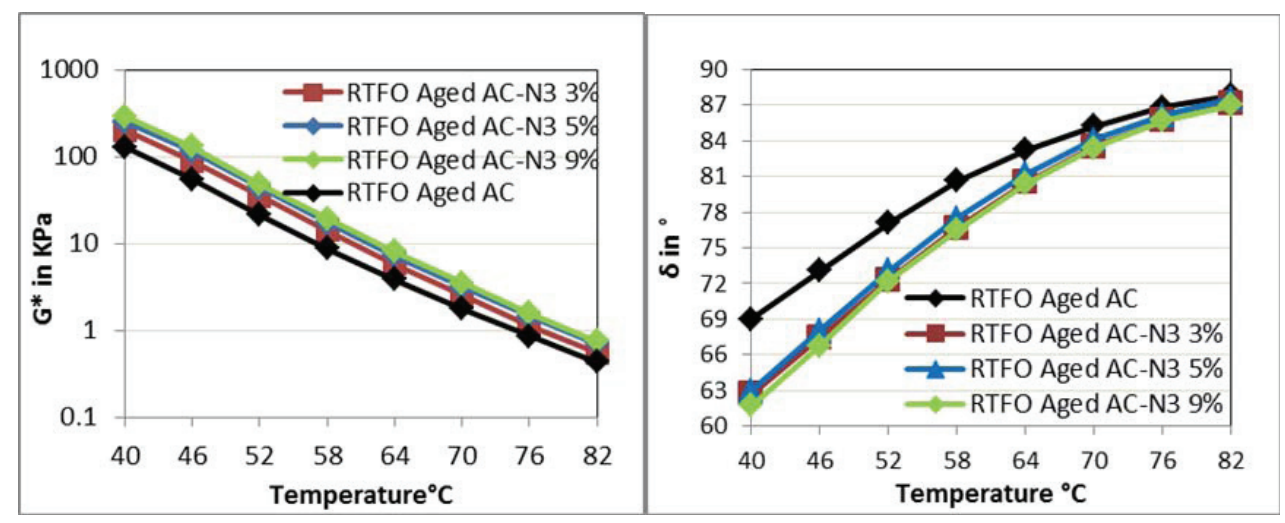

Figure 6. Effect of aging on complex modulus $\left(\mathrm{g}^{*}\right)$ and phase angles $(\delta)$ as a function of temperature for unmodified and modified asphalt binder with $\mathrm{n} 3$ after RTFO aging.
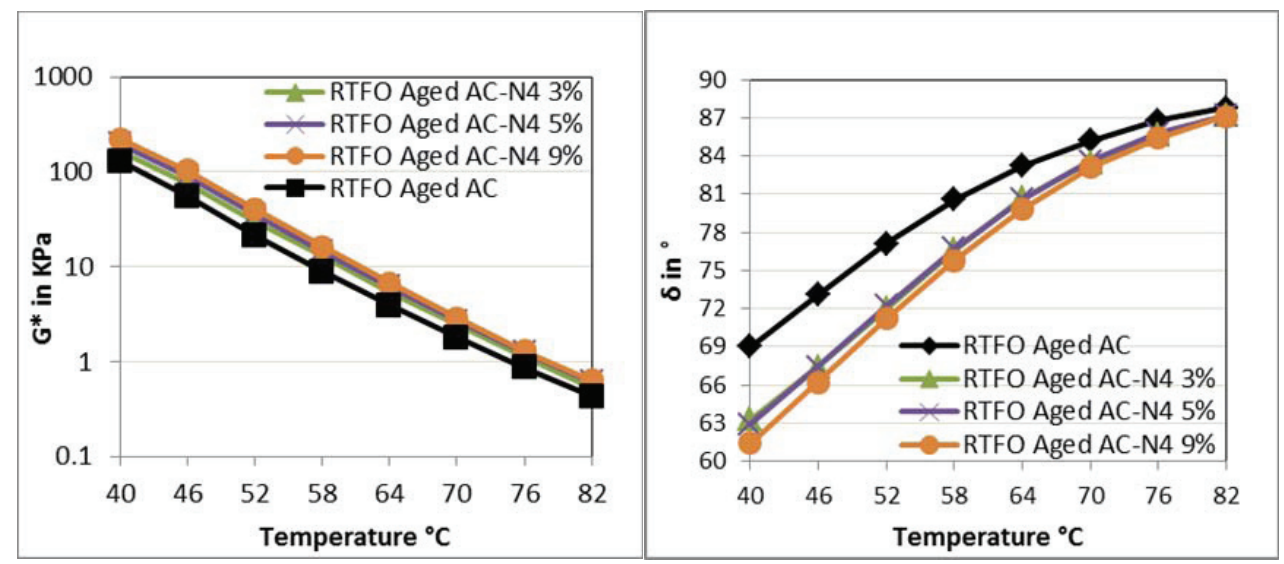

Figure 7. Effect of aging on complex modulus $\left(\mathrm{G}^{*}\right)$ and phase angles $(\delta)$ as a function of temperature for unmodified and modified asphalt binder with $\mathrm{N} 4$ after RTFO aging. 
when permanent deformation is concern. This can be related to the physical properties of each organic modifier that used to modify the montmorillonite nanoclay which affect the compatibility of nanoclay with asphalt binder.

\section{Conclusions}

In this study two types of organic montmorillonite were used to reinforce bitumen with three different concentrations. The physical and rheological properties were investigated before and after short term aging using RTFO aging process. The basic conclusions from this study can be drawn as follows:

The conventional physical properties of OMMTs modified asphalt binder before and after aging showed enhancement as compared to non-modified binder. The retained penetration increases with increasing nanoclay concentration; also higher the nanoclay concentration lower the aging index. From the DSR test results, it can be concluded that the complex shear modulus $\mathrm{G}^{*}$ increased and the phase angle $\delta$ decreased compared to the unmodified binder which led to remarkable improvement in rutting factor $\mathrm{G}^{*} / \sin \delta$, this indicates that the OMMTs had a higher resistance to shear deformation when rutting is concerned. The aging resistance of OMMTs modified asphalt related to the dispersion of the layered silicate inside bitumen molecules that restrict the permeability of the oxygen and thus reduce or at least delay the aging effect of binder which reduce the deformation and rutting distress. In terms of nanoclay type, N3 showed better effect in enhance physical and rheological properties of asphalt binder and rutting resistance of asphalt before and

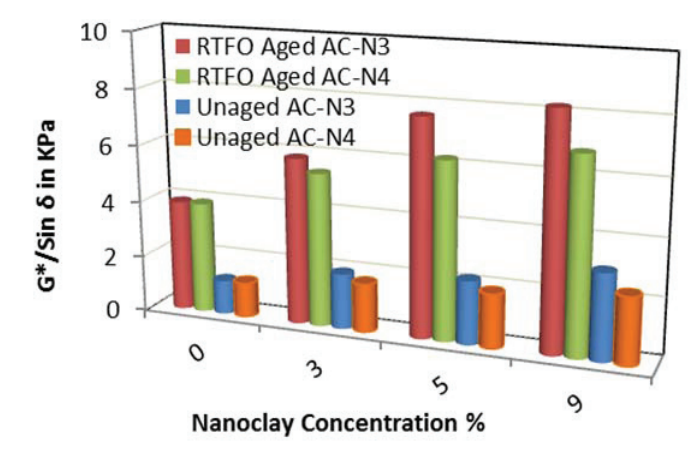

Figure 8. Rutting parameter variation $\left(\mathrm{G}^{*} / \sin \delta\right)$ with the various $\mathrm{N} 3$ and $\mathrm{N} 4$ concentration at $64^{\circ} \mathrm{C}$ before and after aging. after aging process, which contributes to the formation of exfoliated structure in OMMT modified asphalt due to better dispersion of $\mathrm{N} 3$ inside asphalt which related to the types of surface treatment of the montmorillonite MMT that suggested N3 form an exfoliated structure with asphalt binder.

\section{References}

1. You Z, Mills-Beale J et al. (2010). Nanoclay-modified asphalt materials: preparation and characterization, Construction and Building Materials, vol 25(2), 1072-1078.

2. Goh S W, Akin M et al. (2011). Effect of deicing solutions on the tensile strength of micro- or nano-modified asphalt mixture, Construction and Building Materials, vol 25(1), 195-200.

3. Yu J, Wang L et al. (2007). Effect of montmorillonite on properties of styrene-butadiene-styrene copolymer modified bitumen, Polymer Engineering and Science, vol 47(9), 1289-1295.

4. Zhang B, Xi M et al. (2009). The effect of styrenebutadiene-rubber/montmorillonite modification on the characteristics and properties of asphalt, Construction and Building Materials, vol 23(10), 3112-3117.

5. Sureshkumar M S, Filippi S et al. (2010). Internal structure and linear viscoelastic properties of EVA/asphalt nanocomposites, European Polymer Journal, vol 46(4), 621-633.

6. Sureshkumar M S, Stastna J et al. (2010). Rheology of bitumen modified by EVA-organoclay nanocomposites, Journal of Applied Polymer Science, vol 118(1), 557-565.

7. Galooyak S S, Dabir B et al. (2010). Rheological properties and storage stability of bitumen/SBS/montmorillonite composites, Construction and Building Materials, vol 24(3), 300-307.

8. Ghile D B (2006). Effects of nanoclay modification on rheology of bitumen and on performance of asphalt mixtures. Master thesis, the Delft University of Technology, Netherlands.

9. Yu J, Zeng X et al. (2007). Preparation and properties of montmorillonite modified asphalts, Materials Science and Engineering, vol 447(1-2), 233-238.

10. Yu J, Wang X et al. (2010). Effect of various organo modified montmorillonites on the properties of montmorillonite/ bitumen nanocomposites, Journal of Materials in Civil Engineering, vol 22(8), 788-793.

11. Jahromi S G, and Khodaii A (2009). Effects of nanoclay on rheological properties of bitumen binder, Construction and Building Materials, vol 23(8), 2894-2904.

12. Wu S, Wang J et al. (2010). Preparation and fatigue property of nanoclay modified asphalt binder, International Conference on Mechanic Automation and Control Engineering (MACE). 
13. Liu G, Wu S et al. (2009). Modification of bitumen with organic montmorillonitenanoclay, AES - ATEMA, Third International Conference on Advances and Trends in Engineering Materials and their Applications/Montreal, Canada.

14. SHRP-A-367 (1994). Binder Characterization and Evaluation, Strategic Highway Research Program, National Research Council, Washington, D.C, vol 1, 37-38.

15. Boyer R E (1995). Slurry and mirco surfacing performance and experiences, Asphalt Institute Research Center, ThirtyThird Annual Conference of the International Slurry Surfacing Association.

16. AASHTO T-240 (1995). Standard Test Method for Determining the Effect of Heat and Air on a Moving Film of Asphalt (Rolling Thin-Film Oven Test) RTFO, American Association of State Highway and Transportation Officials, Washington DC, USA.

17. ASTM D5 (1986). Standard Test Method for Penetration of Bituminous Material, Annual Book of ASTM Standards, American Society for Testing and Material (ASTM), USA, vol 04.03.

18. ASTM D36 (1986). Standard Test Method for Softening Point of Bituminous Material, Annual Book of ASTM Standards, American Society for Testing and Material (ASTM), USA, vol 04.03.

19. ASTM D4402 (1987). Standard Test Method for Viscosity Determinations of Unfilled Asphalts Using the Brookfield
Thermo Sell Apparatus, Annual Book of ASTM Standards, American Society for Testing and Material (ASTM), USA, vol 04.03.

20. Anderson D A, Christensen D W et al. (1994). Binder characterization and evaluation, Physical Characterization, Strategic Highway Research Program, National Research Council, Washington, DC, vol 3, 475.

21. The Asphalt Institute (2007). The Asphalt Handbook, Manuel Series No: 4 (MS-4), $7^{\text {th }}$ Edn., USA.

22. Kim Y R (2009). Modeling of Asphalt Concrete. Book of McGraw-Hill Publishers, $1^{\text {st }}$ Edn., American Society of Civil Engineers (ASCE).

23. SHRP-A-410 (1994). Superior Performing Asphalt Pavements (Superpave): the product of the SHRP Asphalt Research Program, Strategic Highway Research Program, National Research Council, Washington, D.C, 29-33.

24. AASHTO TP5-93 (1995). Provisional Standard Test Method for Determining the Rheological Properties of Asphalt Binder Using a Dynamic Shear Rheometer, American Association of State Highway and Transportation Officials, Washington DC, USA.

25. Bahia H U, Zhai $H$ et al. (2001). Development of binder specification parameters based on characterization of damage behavior, Journal of the Association of Asphalt Paving Technologists, vol 70, 442-470.

26. Kandhal P S (2005). Selection of bitumen for paving highways in India, Indian Highways, vol 33(7), 17-27. 